\title{
Extended-Family Resources and Racial Inequality in the Transition to Homeownership
}

\author{
Matthew Hall and \\ Department of Sociology and Institute of Government and Public Affairs, University of Illinois at \\ Chicago

\section{Kyle Crowder} \\ Department of Sociology and Carolina Population Center, University of North Carolina - Chapel \\ Hill
}

\begin{abstract}
We use longitudinal data from the Panel Study of Income Dynamics to examine how access to financial resources in the extended family affects the accumulation of wealth among non-owners and how these resources subsequently affect transitioning into homeownership. Our findings show that economic conditions of the extended family have substantial effects on non-owners' wealth accumulation and likelihood of becoming homeowners, even after adjusting for individual sociodemographic and economic characteristics. We find significant effects of extended-family wealth for both black and white households, but effects of extended-family income insufficiency for blacks only. Consequently, limited access to wealth and greater level of poverty in the extended family hamper blacks' transition to homeownership. Our results show that the level of extended-family wealth necessary for black householders to equalize their likelihood of becoming homeowners with whites is very high. In fact, our findings indicate that white householders embedded in extended families with no net wealth are just as likely to make the transition to ownership as are black householders with affluent extended families. These findings support arguments related to the importance of extended-family resources in processes of residential attainment but also point to important racial differences in not only levels but also consequences of these family resources.
\end{abstract}

\begin{abstract}
While the burst of the housing bubble has focused attention on the risks associated with homeownership, equity in housing still constitutes the single largest share of the typical American family's net worth. Ownership also remains deeply immersed into the American ethos as a cultural marker of "having made it," and the transition into ownership continues to be regarded as a major step in the life cycle by a majority of Americans (Perin 1977; Rohe and Watson 2007). The benefits of ownership are not merely limited to the individual, as neighborhoods are also strengthened by residents with financial, social, and political stakes in their communities (Rohe, McCarthy, and Van Zandt 2000). With these positive qualities of ownership in mind, the fact that black households are two-thirds as likely to own housing as white households (U.S. Census Bureau 2010) is indicative of a powerful form of social and economic inequality.
\end{abstract}

(C) 2011 Elsevier Inc. All rights reserved.

*Direct correspondence to: Matthew Hall, 815 W. Van Buren St, Chicago IL 60607. mshall@uic.edu.

Publisher's Disclaimer: This is a PDF file of an unedited manuscript that has been accepted for publication. As a service to our customers we are providing this early version of the manuscript. The manuscript will undergo copyediting, typesetting, and review of the resulting proof before it is published in its final citable form. Please note that during the production process errors may be discovered which could affect the content, and all legal disclaimers that apply to the journal pertain. 
Research seeking to explain the racial disparity in ownership is abundant, and generally has considered the roles of individual-level socioeconomic characteristics, such as income and education, and institutional and contextual factors, such as discrimination and segregation, as primary antecedents. More recent scholarship has emphasized the roles of extendedfamily economic resources, particularly parental wealth, in explaining racial differences in residential attainment (Charles and Hurst 2002; Crowder, South, and Chavez 2006; Conley 1999; Oliver and Shapiro 1995). The implication of these studies is that families rely not only on their own economic resources, but on those of non-household members to secure more desirable residential arrangements. Residential decision-making - including whether to move, to purchase a home, the price range that binds the housing search - is thus influenced by the economic capacity of others to which a household maintains close ties.

Existing empirical research, however, has focused almost solely on the economic capacity of parents. In actuality, families may draw on the assistance of not only parents, but siblings, grandparents, uncles, aunts, in-laws, and other members of the extended family. The extant literature has also been rather narrowly directed at wealth, despite the fact that the financial burden of having to provide assistance to others in need can also influence wealth accumulation and the ability to buy housing, albeit in the reverse direction (i.e., hindering ownership). The fact that black households are disadvantaged not only in terms of their access to potential sources of outside wealth (i.e., parental and extended-family wealth), but also in their social relationship to more economically vulnerable family members, suggests a doubly-disadvantaging process that inhibits black families from acquiring housing. To date, little research has been dedicated to delineating the nature of this dual disadvantage or the effect on racial differences in housing acquisition.

A further limitation of past research is that it has yet to consider the processes through which extrahousehold family resources influence residential outcomes. The assumption of research highlighting parental wealth is often that affluent parents ease the transition into ownership by assisting with downpayments or providing other forms of direct financial assistance (e.g., paying closing costs or supplementing mortgage payments). Certainly, these are convincing explanations, but they may not be the only means through which wealth operates. Being embedded in wealthy family networks may also provide a real or perceived safety net against the risks of ownership or be associated with socialization processes that place differential value on the importance of ownership (see Conley 1999).

In this study, we use longitudinal data from the Panel Study of Income Dynamics, 19852005 to address these shortcomings of prior research by exploring how levels of wealth and poverty among members of the extended family (e.g., grandparents, parents, siblings, children) affect the transition to homeownership, and how disparities in extended-family resources affect racial inequality in ownership. We also provide evidence on how extrahousehold financial resources affect homeownership by examining whether their effects are explained by direct financial transfers between family members. Four questions guide our research:

1. How do differences in extended-family wealth and poverty affect the accumulation of resources available for the transition to ownership?

2. To what extent is the racial disparity in the transition to homeownership explained by racial differences in extended-family wealth and poverty?

3. Are the effects of extended-family economic resources on the transition to ownership different for white and black households?

4. And, are the effects of extended-family wealth and poverty explained by the receipt and provision of economic help from/to others outside the household? 


\section{Background}

Recent data reports the black-white gap in homeownership to be about 29 percentage points, with 74 percent of white householders owning compared to 46 percent of black householders (U.S. Census Bureau 2010); and while the racial gap in homeownership has declined since the middle of the twentieth century (Collins and Margo 2001) it remains large (Shapiro 2004; Simmons 2001) and may again be growing with the current racial differences in foreclosure rates (Immergluck 2009; Rugh and Massey 2010).

The conventional framework for explaining this disparity in the levels of homeownership is the microeconomic thesis which views inequalities in residential attainment as a consequence of group differences in socioeconomic resources. Given the powerful role of income, education and (own) wealth in shaping the acquisition and value of housing (Alba and Logan 1992; Boehm 1993; Krivo and Kaufman 2004; Rosenbaum 1996), it follows that individuals and groups, such as African Americans, with fewer economic resources should have less attractive residential options, and a more difficult time becoming homeowners, than their more advantaged, white counterparts.

Yet, group socioeconomic differences do not appear to explain disparities between blacks and whites in residential outcomes. Indeed, the segregation literature suggests that the role played by income in explaining patterns of black-white residential segregation is modest at best (Fischer 2003; Iceland and Wilkes 2006; Massey and Denton 1993). Similarly, significant racial differences in homeownership exist even among households with similar socioeconomic resources (Alba and Logan 1992; Rosenbaum 1996). To explain these persistent racial disparities in residential outcomes, the stratification model emphasizes the barriers and constraints faced by minority groups in seeking, financing, and purchasing housing (see Alba and Logan 1992). This perspective typically draws attention to the dual housing markets created by discriminatory practices of banks and mortgage lenders (Squires and Kim 1995), real estate agents (Yinger 1995), and federal transportation, tax, and housing policies (Massey and Denton 1993). Racial prejudices and stereotypes held by dominant group members further restrict the residential circumstances of minority groups by influencing their willingness - manifest in both in- and out-migration decisions and resistance to newcomers - to share neighborhoods with members of other racial groups (Bobo and Zubrinksy 2000; Charles 2000, 2006; Krysan 2002; Krysan et al. 2008, 2009). The stratification model does not dismiss the importance of socioeconomic status in residential attainment, but instead asserts that even after taking economic resources into account racial disparities in residential outcomes will persist.

Housing research has long acknowledged the role of a household's own wealth for attaining more attractive residential circumstances (Boehm 1993; Charles and Hurst 2002; Di and Liu 2007). Household wealth facilitates the acquisition of housing, as well as plays a prominent role in its overall value, physical quality, and neighborhood location. Wealth eases the transition to homeownership by contributing to downpayments and minimizing the ancillary costs associated with borrowing which, in turn, enable more favorable mortgage terms. Household wealth also provides a cushion to cover the costs of relocating and potential repairs or renovations that are often associated with new ownership. These financial advantages translate into a wider "action space," increasing the likelihood that homeseekers will find a housing bundle that meets or exceeds their demands. Individual assets can also act as a private safety net from the potentially devastating effects of financial difficulties and emergencies that can prevent households from buying housing (Conley 1999).

The racial gap in household wealth is enormous, and following from the microeconomic perspective, its presence raises the possibility that differences between blacks and whites in 
homeowership may partially result from differences in household wealth. As of 2004, the median net worth of white households was $\$ 113,822$, while that for black households was $\$ 8,650$. Even after excluding wealth due to housing equity, the gap remains large and far exceeds the respective gap in earnings (U.S. Census Bureau 2010). To no surprise, blacks are underrepresented among the very affluent - only one percent of those in the 99th percentile of the wealth distribution are black (Keister 2000) - and overrepresented among those with zero or negative net worth (the modal category for black householders) (U.S. Census Bureau 2010). Clearly then, household wealth is an important consideration for better understanding the underlying processes maintaining racial inequality in rates of homeownership.

\section{Extended-Family Economic Resources}

While own-household wealth has been featured prominently in housing research, more recently, researchers have drawn attention to the impact of extended-family wealth, such as that of parents, on residential attainment (Conley 1999; Charles and Hurst 2002; Crowder et al. 2006; Oliver and Shapiro 1995; Shapiro 2004). Much like own-household wealth, having wealthy relatives may promote homeownership via their contributions to downpayments and associated mortgage costs, by supplementing monthly loan payments, or providing a safety net that facilitates a housing purchase. These propositions are at least partially supported by existing research. For example, Mayer and Engelhardt (1996) find that, after adjusting for socioeconomic and demographic characteristics, householders who received financial gifts are able to purchase homes sooner, make larger downpayments, and buy homes of greater value than those who did not receive gifts. Similarly, Charles and Hurst (2002) show that parental wealth exerts a strong, positive effect on whether housing mortgage applications are approved.

Given the large wealth disparity between blacks and whites, not only are African Americans at a disadvantage with regards to their own financial assets, but with that of their parents and extended families as well. This observation is reflected in the fact that blacks are less likely to receive inheritances or other forms of intergenerational wealth transfer than are whites. Whereas more than a quarter of white households report having received an inheritance, only 10 percent of black households do, and among those receiving an inheritance, white households see, on average, about one-third more than black households (Menchik and Jianakopolos 1997). ${ }^{1}$ Jayakody (1998) reports that this disadvantage in wealth transfers is especially pronounced at the lower end of the income distribution, where low-income whites hold a 9 percentage point premium over low-income blacks in the likelihood of parental financial support.

Accordingly, Charles and Hurst (2002: 292-3) find that part of the racial gap in mortgage application acceptance is explained by parental wealth, concluding that "there is a large difference between blacks and whites in their ability to depend on their families for downpayment assistance, and that this help significantly makes mortgage application more likely." Likewise, interviewing young homeowners about how they generated money for their down payments, Shapiro (2004) reports that white respondents were much more likely to have received assistance from their parents than were black respondents; and among those receiving support, whites received considerably more than blacks.

\footnotetext{
${ }_{1}$ Black households received $\$ 57,108$ in inheritance, compared to $\$ 75,197$ for whites (see Menchik and Jianakopolos 1997, Table 1, pg. 431). Using an older cohort of data from the National Longitudinal Survey of Mature Men, the authors find the racial differences in the receipt of inheritance, among men between the ages of 55 and 69 to be even larger ( $0.5 \%$ for blacks vs. $17.3 \%$ for whites), as well as the relative magnitude of the value of those transfers ( $\$ 4,157$ for blacks vs. $\$ 16,264$ for whites).
} 
Certainly, existing research linking parental wealth and racial inequality in ownership is informative, but it is limited in some important ways. First, by focusing on racial differences in inheritance, other major financial transfers and on the disposition of financing applications during the purchase process, most past research may underestimate the overall effect of parental wealth on racial differences in homeownership. The availability of financial resources from family members may affect the likelihood of deciding to attempt a home purchase in the first place, raising the importance of examining racial differences in family wealth for all nonowners, not just those successful in buying a home.

Second, existing research has, for the most part, tended to focus solely on the effects of parents' wealth, reflecting an assumption that the flow of financial transfers from parents to children is unique and unidirectional (for exceptions, see Chiteji and Hamilton 2005; Cox 2008; Eriksen and Gerstel 2002; White and Reidmann 1990). However, parents are not just the providers, but also the recipients of financial assistance from their adult children (McGarry and Schoeni 1995). Family financial transfers also extend beyond the parent-child dyad and flow between children and their grandparents, siblings, or other close relatives, and there are likely to be pronounced racial differences in the level of wealth within these broader family networks. Thus, understanding racial differences in the transition to ownership requires attention to more inclusive measures of access to financial resources that tap into socioeconomic conditions for a broader set of extended-family members.

For good reason, past research has directed attention largely to the benefits of access to family wealth (e.g., Conley 1999; Oliver and Shapiro 1995; Shapiro 2004). Yet often overlooked are the detrimental effects of economic hardships in the extended family. Extending the assumptions about how wealth shapes ownership, having poor family members will potentially reduce the likelihood of receiving aid for downpayments, mortgage payments, and other costs associated with the transition to ownership. But it will also increase the likelihood that household resources will be diverted from the purchase of a home and toward the provision of help for those in need. Consequently, households connected to economically-poor extended families should be more likely to provide financial assistance for needy family members, and in turn inhibiting the accumulation of resources necessary for the purchase of a home.

Even in the absence of the actual financial transfers to those in needs, households connected to poor extended families may be more reluctant to dedicate resources toward the purchase of a home for fear of diverting funds away from needy family members in the future. In line with this reasoning, Heflin and Pattillo (2002) find that having a sibling in poverty greatly reduces the odds of having a bank account and owning a home. By contrast, for households embedded in extended-family networks with greater income sufficiency, the likelihood of setting aside funds for extended family members should be relatively low. Thus, the relationship between residential attainment and extended family financial resources is multifaceted and multidirectional.

Considering the more financially-strained social networks of black families, these issues are particularly salient for understanding racial inequality in homeownership. As Heflin and Pattillo (2006) note, African Americans are less likely to have cross-class kin ties that are beneficial in nature and more likely to have kin ties that could produce financial burden. They show that middle-class blacks are far more likely to have a poor sibling than middleclass whites, and poor blacks are much less likely to have a middle-class sibling than are poor whites. These racial differences in the composition of extended families are compounded by the fact that racial homophily in social networks leads to non-familial social contacts among African Americans that are much more likely to be poor (Currarini, Jackson, Pin 2009; McPherson, Smith-Lovin, and Cook 2001). ${ }^{2}$ 
Racial differences in levels of extended-family financial resources thus potentially act as a powerful source of residential stratification. Moreover, the substantive impact of extendedfamily wealth and poverty may also differ by race. Discrimination in housing and lending markets may inhibit the ability of black nonowners to translate their own or their families' economic resources into homeownership, such that even affluent blacks are less likely to become homeowners than less-advantaged whites. Thus, under this "strong version" of residential stratification (see Alba and Logan 1992), the effects of extended-family wealth and poverty would be weaker black than for white nonowners. Obversely, "the weak version" of stratification holds that only the most-advantaged minority nonowners are able to successfully make the transition to homeownership, such that the effects of wealth and poverty on becoming a homeowner are stronger for blacks than whites.

A final area in which research is lacking is identifying the mechanisms through which extended-family resources influence homeownership. The assumption made in most past research is that extended-family wealth increases the likelihood becoming a homeowner by increasing households' own levels of wealth. That is, monetary transfers from affluent extended families allow households to accumulate enough wealth to contribute large downpayments to loans, to make mortgage payments, and to offset the many peripheral costs of purchasing housing. Similarly, the personal wealth of nonowners available for the acquisition of housing should be reduced when they are providing assistance to extendedfamily members in need. Consequently, the link between extended-family wealth/poverty and the likelihood of homeownership should be reduced or eliminated once own-household wealth is accounted for.

It is possible, however, that the effects of extended-family resources affect the transition to ownership in less material ways. As noted above, extended-family wealth may, for example, provide an assurance that financial support is readily available if a family is unable to make a mortgage payment, pay the gas bill, repair a leaky roof, or deal with a host of other problems associated with ownership. As Shapiro (2004) explains, the security offered by wealth safety nets is just as much psychological as financial. Similarly, even if support for poor extended-family members is not currently provided, a perception that these family members will eventually require help might influence residential decisions. Extended-family wealth and poverty may also operate via socialization processes if wealthy families attach greater value to homeownership than less-wealthy families. Thus, examining the extent to which the effects of extended-family resources on the transition to homeownership are directly mediated by the amounts of financial help received from, and provided to, others in the extended family provides an opportunity to further develop the understanding of the mechanisms through which family conditions influence residential attainment, and act to maintain racial inequality.

\footnotetext{
2 These issues will be of further interest to race scholars considering the longstanding debate regarding differentials in the "reach" and "strength" of black and white social networks. Social networks, among black families, have conventionally been accepted as tighter (drawing from closer contacts) and stronger (greater dependence and exposure), due to either cultural proclivities (Sudarkasa 1996) or to structural disadvantage that increase blacks' reliance on extended and fictive kin ties (Stack 1974). However, recent research has questioned these assumptions by noting the high prevalence of family-disorganization in the black community (Wilson 1987) and their deteriorating economic position (Roschelle 1997). Regardless of the process, there is some evidence to suggest that kin support among blacks is less strong than once believed. Research has consistently found that black adult children are less likely to receive financial assistance than white adult children (Jayakody 1998; Lee and Aytac 1998). Berry (2006) finds that blacks are less likely to receive financial support from their parents to the degree of 50 percent, and among those receiving intergenerational support, blacks receive 50 percent less than whites. Of course, social support can come in many forms, such as through close personal relationships or coresidence. Indeed, Raley (1995) reports that while single black women are less likely than whites to receive financial assistance from relatives, they have closer contact with parents and siblings and are more likely to be living with relatives.
} 


\section{Data and Methods}

\section{Data}

To estimate the impact of wealth and extended-family resources on the residential attainment process, we use longitudinal data from the Panel Study of Income Dynamics (PSID), a well-known longitudinal survey of U.S. residents and their families (Hill 1992). The initial panel of approximately 5,000 families (about 18,000 individuals) was interviewed annually from the survey's initiation in 1968 through 1997 and has been interviewed biennially since then. New families have been added to the panel as children and other members of original panel families form their own households so that the panel in later years contains information on multiple householders spawning from the original panel families. Sample attrition has been modest, especially in more recent years, and has not compromised the representativeness of the sample (Duncan and Hill 1989). In comparison to other longitudinal studies, the PSID is uniquely suited for this analysis for two reasons. First, these data contain an abundance of information regarding both household and extendedfamily assets. Second, information is collected at each interview regarding the receipt and provision of financial assistance from and to family members and others outside of the family unit.

In order to take full advantage of the longitudinal nature of the PSID, we structure the data in person-period format with each observation referring to the period between PSID interviews. Although it is possible to define annual intervals for most years of the PSID, we use two-year intervals in order to maintain consistency with observations after 1997 when the PSID adopted a biennial interview schedule. We restrict our sample to black and nonHispanic white respondents who were classified as household heads at the beginning or end of a two-year observation interval. Since this analysis focuses on the transition to ownership, our sample includes only those householders who did not own their home at the beginning of each observation window. Comprehensive information on the wealth of PSID households was first collected in 1984 so we limit our analysis to observation periods between 1985 and 2005. In total, our sample includes 8,127 householders contributing a total of 35,776 personperiod observations.

The two primary dependent variables in this analysis are household wealth and the transition to homeownership. Information on household wealth or financial assets-including checking and saving accounts, businesses owned, vehicles, stocks, bonds, trusts, and other real estate-were collected by PSID in 1984, 1989, 1994, 1999, and each biennial interview thereafter. We use the 1984 wealth data to measure household wealth in observation periods beginning in years between 1985 and 1988; the 1989 wealth data for the 1989 through 1993 observations; the 1994 measures for the 1994 to 1998 periods; and the biennial wealth values for observation periods beginning in 1999 and later years. We adjust these wealth values to thousands of year 2000 dollars and log-transform them (negative and zero values are recoded as .01) for use in regression analyses. ${ }^{3}$ Our second dependent variable, the transition to homeownership, is measured as a dichotomous variable taking a value of 1 for those nonowner householders at the beginning of the observation interval (time $t$ ) who owned their home by the end of the interval (time $t+2$ ).

\footnotetext{
${ }^{3}$ Measures of income and wealth (at the both the household and extended family levels) are highly skewed and models with untransformed versions of these variables show strong signs of heteroskedasticity. Nevertheless, the results from these models are substantively consistent with the models we present using transformed variables. We also considered models in which household wealth was transformed using an inverse hyperbolic since transformation, which has the benefit of accommodating non-positive values of wealth. The results of from the IHS-transformed wealth models are consistent with the logged-wealth results, and due to the complexity of interpreting results from the IHS transformation, we show the log-transformed results here.
} 
In addition to household wealth, measured at (or before) the beginning of the observation period, key predictor variables for this analysis are measures of extended-family wealth and poverty. Past research utilizing the PSID data has tested the effects of family resources using a simple measure of parental wealth (e.g., Crowder et al. 2006). This strategy has several important drawbacks. First, the PSID's parental wealth variables are measured only in 1988, potentially undermining the validity of the variable as a measure of the family resources available to the household at later or earlier observation points. In addition, these parental wealth variables are based on the householder's estimate of the value of her/his parents' assets and those of her/his spouse's parents. Most importantly, the focus only on parental wealth means that other sources of family wealth that may be available to the householder for example, from siblings, grandparents, and other extended family members - are completely ignored.

Given these drawbacks, we extend past research by developing a measure of the average level of wealth held by members of the extended family. This strategy takes advantage of the unique structure of the PSID panel in which family members who move out of an original panel household are added to the panel as independent households. In many cases, these split-off families represent multiple householders from multiple generations of an original PSID family. As a result, for the vast majority of PSID respondents we have data about the households headed by several members of the extended family. While limitations of the PSID prevent us from considering types of specific relationships between members of the same extended family, we do know that younger-generation family members (e.g., nieces, nephews, and nonresident children) compose about 30 percent of the average extended family network, same-generation members (e.g., siblings, cousins) make up nearly 45 percent, another 21 percent is in the parents' generation (e.g., parents, aunts, uncles), and the grandparents' generation constitutes about 5 percent of the extended family.

Using the wealth measures paralleling those described above, we calculate the average level of wealth, including the net value of all owned property, for PSID households related back to the same original PSID family, including the householders' parents, grandparents, aunts, uncles, and any other relatives appearing in the PSID data. ${ }^{4}$ Along these same lines, to measure the income sufficiency for households in the extended-family network, we ascertain the poverty status of each member of the extended family - employing the thresholds developed by Grieger, Schoeni, and Danzinger (2009) - and calculate the percentage of the extended family that is poor. ${ }^{5}$ To avoid linearity between immediate and extended-family resources, the measures of extended-family wealth and poverty exclude information from the individual's own household. Thus even for those householders related back to the same root PSID family, the measures of extended-family resources are based on a unique set of outside related households. ${ }^{6}$ As with household wealth, extended-family wealth is measured in thousands of constant year 2000 dollars and log-transformed in regression analyses. ${ }^{7}$

Our models also include measures of the provision and receipt of financial assistance from others outside of the household. We use questions asked by the PSID regarding the amount

\footnotetext{
${ }^{4}$ In supplemental models available upon request, we considered the standard deviation of extended-family wealth, finding it to exert a very small effect on own wealth accumulation and on the transition to homeownership.

5 The typical PSID householder in our sample has wealth and poverty information for just under 27 members of their extended family (representing an average of 9.8 extended-family households). As the PSID does not sample non-household members of respondents' families, we do not have complete information on the financial resources of every extended family member. Accordingly, our extended family measures assess average levels of wealth and poverty among sampled extended-family members, rather than total wealth and poverty across the entire extended family. We assume that extended family members for which we do have complete information represent a cross-section of respondents' full extended-family networks, and that the frequency and magnitude of any violations of this assumption do not vary systematically by race. As our main focus is on the potential for financial assistance from (or to) extended-family members, averaging financial capacity across members of the extended family is a reasonable (if not superior) approach to take.
} 
of money households received from, and the amount of financial help provided to, family or friends outside of the household. We take advantage of responses to these questions in several sequential interview years to estimate the total amounts of financial help provided to, and received from, those outside of the immediate household during the five years leading up to and including the observation period. ${ }^{8}$ Values for these measures are normalized to constant year 2000 dollars and log-transformed.

Additional explanatory variables capture other social, demographic, and economic characteristics of individuals and households that have been shown to be of importance in previous research. Race is a dummy variable distinguishing white from black householders (black=1). The householder's education is captured as the number of years of schooling completed by the beginning of the observation period. Due to the volatility in income over time (see Solon 1992), we measure income as the average taxable income (in thousands of year-2000 dollars) of the respondent and spouse over the three years preceding the observation period. Age of the household head, an important measure of life cycle demands for housing, is measured in linear years. We distinguish between male and female household heads (female $=1$ ). Marital status is a dichotomous term differentiating householders who are married or long-term cohabitors with the unmarried at the beginning of the period. The presence of children, another key determinant of housing demands, is measured as the number of children under the age of 18 in the household. We also include measures for residential density (the number of people per room in the home), whether the householder lives in public versus private housing (public $=1$ ), whether or not the householder has resided in the same address for at least 3 years as of the beginning of the observation interval, and whether the household was newly formed during the observation period. Lastly, we control for possible temporal changes in the accumulation of wealth and ownership transition with a variable for year of observation.

\section{Methods}

We employ regression techniques to estimate two outcomes. To get a basic assessment of the extent to which extended-family resources contribute to householders' own levels of wealth, our first set of models uses OLS regression to examine the effect of key explanatory variables on logged household wealth as of the beginning of the two-year observation period (time $t$ ) for the nonowners in our sample. Next, we use logistic regression models to predict the impact of the extended-family wealth and poverty on the likelihood of transitioning to ownership by the end of the observation interval $(t+2)$. Our models do not differentiate between first and later transitions to ownership, so if householders who are homeowners become nonowners, they re-enter the sample. ${ }^{9}$ To correct for the non-independence of

\footnotetext{
${ }^{6}$ To address concerns that our measures of extended-family wealth and poverty exclude many members of the extended family, an alternative analytic approach would be to restrict the analysis to PSID respondents with three generations of potential sources of support or need (i.e., whose siblings, parents, and grandparents are also followed). Unfortunately, too few respondents ( $\mathrm{N}=975)$ in our sample of nonowners meet this condition. Supplemental analyses indicate that these individuals are slightly younger than PSID members with fewer generations of extended family present in the PSID but are not significantly different in terms of average levels of extended-family resources or other key characteristics. Similarly, regression models indicate that neither the net probability of transitioning to ownership nor the effects of extended-family wealth nor poverty on this transition vary significantly with the number of generations of family members represented in the PSID data.

${ }^{7}$ During the years of the study there were 1,958 households associated with base PSID families to which no other independent panel households were associated. Since measures of extended-family wealth and income sufficiency cannot be calculated for these lone householders they are excluded from our analysis. We found no evidence that this exclusion affects the representativeness of the sample as these excluded individuals are statistically similar to householders included in the analysis and models that include these lone householders but omit the measures of extended-family resources produce results that parallel models using our effective sample. ${ }^{8}$ We tested several alternative specifications of the variables tapping the provision and receipt of financial help, including measures with alternative temporal lags (between one and five years leading up to and including the observation period) and separate dichotomous indicators for the receipt and provision of any financial help. These alternative strategies produce results that are similar to, but generally weaker than, those presented here.
} 
person-period observations associated with the same householder, the standard errors of all regressors are adjusted using the cluster procedure in Stata (StataCorp 2009).

\section{Results \\ Descriptive Statistics}

Means and standard deviations (in parentheses) for variables used in the analysis are shown in Table 1 for the pooled (black and white) sample and separately for white (middle column) and black (right column) non-owning householders. Several striking racial disparities are shown here. Blacks are much less likely than whites to transition from renting to owning; only 10 percent of black renters became homeowners during the average observation period, while more than twice as many (22 percent) white renters did. The net worth of black renters (about $\$ 11,000$ ) is roughly one-fourth the average for whites (about $\$ 47,000$ ). The racial disparity in extended-family wealth closely parallels this racial gap in household wealth; the average wealth in whites' extended families $(\$ 170,740)$ is about five times larger than the average wealth in blacks' extended families $(\$ 33,570)$. Variation around both of these means - household and extended-family wealth - is also much larger for white than black nonowners. In addition to having markedly lower levels of accessible wealth, the percentage of extended family members living in poverty is nearly four times larger for black than white nonowners ( $34.1 \%$ vs. $9.0 \%$ ). Thus, in comparison to their white counterparts, black nonowners not only have access to fewer wealth resources but are also more likely to be embedded within extended families that require their assistance.

Despite the apparent need for greater support, black renters provided less than half of the financial support to others that white renters did (about $\$ 1,020$ vs. $\$ 2,380$ for blacks and whites, respectively), although this difference must be interpreted in light of the fact that the average black household also holds fewer income and wealth resources to share with others. And, although white renters are less needy of support from others, they received a substantially higher average level of financial assistance from others than did black renters (\$350 and \$1,090 for blacks and whites, respectively). Descriptive statistics for the remaining explanatory variables are consistent with past work: black renters have lower incomes and less schooling than white renters, are more likely to be female, less likely to be married, have more children, and more likely than whites to live in crowded homes and in units that are publically-subsidized.

\section{Household Wealth}

As an intermediate step, the first stage in our analysis examines how extended-family wealth and poverty influence nonowners' own levels of household wealth. Our intention here is not to provide a comprehensive account of wealth accumulation, but more simply to demonstrate the extent to which levels of wealth - and racial inequalities in wealth - are determined by the wealth and poverty status of the extended family. OLS regression coefficients and robust, cluster-adjusted standard errors for models predicting household net worth for our sample of black and white renters are shown in Table 2. The first column shows the gross (unadjusted) black-white difference in wealth. As expected from the descriptive differences in Table 1, African American nonowners have a large and statistically significant wealth disadvantage relative to white households of about $93 \%$ $\left(\mathrm{e}^{-2.69}-1\right)$.

\footnotetext{
${ }^{9}$ In supplemental models, we tested differences in the number of transitions. While return owners differ from first-time owners in terms of sociodemographic characteristics, there are no significant differences in the effects of extended-family wealth or poverty.
} 
To explore this explanation, our second model includes terms for the age, sex, and educational attainment of the household head, and logged taxable household income. As expected, wealth increases with age, educational attainment, and income, and is lower for households headed by women. A comparison of Models 1 and 2 in Table 2 shows that controlling for these sociodemographic characteristics explains about close to half (47.2\%) of the black wealth disadvantage, but the difference in household wealth between black and white nonowners remains large and statistically significant.

We next turn to whether the racial disparity in household wealth among renters is a function of racial differences in the economic capacity of extended families. As expected, the coefficients on extended-family wealth and poverty in Model 3 of Table 2 indicate that extended family financial resources influence households' own wealth in important ways. Net of socioeconomic characteristics of the householder and the immediate family, a ten percent increase in extended-family wealth increases household wealth by about 2 percent. Along these same lines, a ten percentage point increase in extended family poverty reduces nonowners' own wealth by about $10 \%$. Thus, even net of any indirect effect operating through the education and income of the householder, these results highlight the direct impact of extended-family resources on the accumulation of wealth for non-owners.

Even more noteworthy is the fact that with these two characteristics of householders' extended families included in the model, the original racial wealth gap between white and black is reduced by another fifth. Clearly then, part of the story explaining the black-white wealth disparity is that white households are situated within family networks with greater wealth and lower poverty than black households. Yet, despite finding that differences in extended-family economic resources account for a sizeable share of the racial wealth gap, when the wealth and poverty levels of extended families are held constant, black nonowners still hold about $76 \%\left(\mathrm{e}^{-.87}-1\right)$ less wealth than white nonowners. Thus, these findings highlight not only the importance of extended-family characteristics in the accumulation of resources needed to facilitate the transition to ownership, but also persistent racial inequality in these resources.

\section{Transition to Homeownership}

What role does extended-family wealth and poverty play in determining whether renters become homeowners? We address this theoretically-relevant question by estimating the likelihood that nonowners at the start of each observation interval become homeowners by the end of the two-year period. The logistic regression coefficients in Table 3 are interpreted as the log-odds of renters transitioning to ownership given a one-unit change in the given explanatory variable. The first model simply reports the gross (unadjusted) racial difference in the log-odds of becoming homeowners. The negative coefficient for race in this model indicates that black renters are $62 \%$ less likely $\left(\mathrm{e}^{-.969}-1\right)$ than white renters to make the transition to ownership in a given observation window. In the left panel of Figure 1, we convert the log-odds in Model 1 of Table 3 to probabilities of becoming a homeowner. Corresponding with the descriptive statistics in Table 1, the probability for white householders (.22) is more than twice that for black householders (.10), a difference that is highly statistically significant $(\mathrm{p}<.001)$.

In Model 2, we test the possibility that the lower probability of transitioning to ownership among blacks is due to racial differences in sociodemographic and housing characteristics as of the beginning of the observation period. The effects of these explanatory variables are consistent with previous research: the likelihood of becoming a homeowner is higher for married householders and for those with more children, and lower for households headed by women, those living in more crowded conditions, those residing in the same location for at least three years, and among new householders and those living in public housing. The 
important finding, however, is that while these factors mediate the black ownership disadvantaged by about one-quarter (from -.969 in Model 1 to -.708 in Model 2), black households remain significantly less likely to transition to ownership than whites with similar sociodemographic characteristics.

The third model in Table 3 considers the roles of the respondent's education and income of the immediate household. As predicted by the microeconomic perspective, both variables exert strong positive effects on the log-odds of transitioning to ownership. Net of other factors, the odds of ownership increase by about 57 percent $\left(\mathrm{e}^{(.474)(.950)}\right)$ for every onestandard-deviation increase in the log-scale of income, and by about 5 percent $\left(\mathrm{e}^{.045}\right)$ with each year of schooling completed. However, while the addition of these terms further decreases the negative black effect by about a quarter (from -.708 to -.520 ), the black ownership disadvantage is still large and highly significant, lending some support to the stratification perspective's emphasis on lingering barriers in the housing and lending market for black homeseekers.

In Model 4 of Table 3 we investigate the extent to which this net black disadvantage in the transition to ownership is attributable to racial differences in extended-family wealth and poverty. Consistent with our expectations, the transition to homeownership is positively and significantly influenced by the average level of wealth in the extended family, even net of the resources and other characteristics of the immediate household. Specifically, an increase of one standard deviation in the log-scale of extended-family wealth is associated with a 21 percent increase $\left(\mathrm{e}^{(.055)(3.529)}\right)$ in the odds of transitioning to ownership in a given observation period. By contrast, the likelihood of becoming a homeowner appears to be unaffected by the percentage of extended family members living in poverty. Nevertheless, controlling for extended-family resources accounts for a modest portion of the remaining racial gap in homeownership; the coefficient for black race is reduced by about 18 percent (from -.520 to - 426 ) between Models 3 and 4 . However, the statistically significant residual race coefficient indicates that black householders are much less likely to become homeowners than are white householders with similar levels of income in the household and resources in the extended family.

In Model 5, we introduce interaction terms to test for racial differences in the effects of extended-family economic resources on the transition to ownership. The results indicate that extended-family wealth operates similarly for white and black householders, but that the effect of extended family poverty varies by race. Specifically, the non-significant coefficient for extended family poverty in Model 5 indicates that for whites the likelihood of transitioning to ownership is not affected by the sufficiency of incomes earned by members of the extended family, but, as indicated by the negative and statistically significant coefficient for the interaction term, the hypothesized effect is significantly stronger for blacks. Thus, in contrast to whites, the transition to ownership among black householders is not only significantly less likely but also more contingent on the sufficiency of resources in the extended family - a finding consistent with the weak version of the stratification perspective. Specifically, black householders are less likely than similarly situated whites to make the transition to ownership if members of their extended family have incomes below the poverty line.

Models 6 and 7 of Table 3 test two explanations for how extended-family economic resources influence ownership: via their effects on own household wealth and through the direct provision/receipt of financial assistance. We first add households' own wealth to the equation and find that, as expected, own wealth positively affects the likelihood of transitioning to ownership. Specifically, net of household income and sociodemographic conditions, and extended-family resources, a one-standard-deviation increase in the log- 
scale of household wealth increases the odds of transitioning to ownership by about 17 percent $\left(\mathrm{e}^{(.034)(4.614)}\right)$. Most importantly, the results indicate that a relatively small portion of the effect of extended-family wealth on the transition to homeownership operates through own-household wealth. In other words, part of the effect of having a more affluent extended family network on the ability to acquire housing is because those embedded within higherresourced families accumulate higher levels of personal wealth. However, even with own wealth in the equation, a large and significant positive effect of extended-family wealth remains, consistent with the argument that extended-family resources have a more direct influence on the ability to purchase a home.

We next consider whether the effects of extended-family economic resources operate through the direct provision or receipt of financial assistance. The results in Model 7 suggest not. While, the amount of financial support received from others is significantly associated with the likelihood of becoming a homeowner, this association is negative (reducing the logodds of transitioning to ownership), likely reflecting the reluctance or inability of householders that are more financially dependent on others to make the transition to ownership. Moreover, the association between the provision of help to others and the likelihood of transitioning to ownership is far from statistically significant ( $\mathrm{p}=.16$ ). Most importantly, neither extended-family wealth nor poverty (for blacks) is attenuated by the inclusion of either measure of financial transfers. Thus, it appears that extended-family resources influence the transition to homeownership not through the provision of direct financial support, but through more amorphous mechanisms, perhaps by providing a safety net that increases householders' willingness to take the financial risk of ownership or improving the ability to secure financing.

The middle panel of Figure 1 shows predicted probabilities of becoming a homeowner for black and white householders once all of these characteristics of households and their extended families have been accounted for. As can be seen, the likelihood of transitioning for blacks (.11) is still substantially lower than that for whites (.16) with similar levels of household income and wealth and comparable resources in the extended family. What is most striking from the results in Table 3 is the amount of extended-family wealth needed for black householders to meet whites' probability of becoming homeowners. The right panel of Figure 1 demonstrates that racial parity in the likelihood of transitioning to ownership is not achieved until black renters have an enormous advantage in extended-family wealth over whites. Specifically, holding all other variables at their pooled means, the probability of homeownership for black householders' only reaches that of whites, when blacks' extended families have, on average, nearly $\$ 500,000$ more than whites' extended families. Thus, a white householder from an extended family with effectively no financial capital is just as likely to transition from renting to owning as a black household embedded in an extended family with a level of wealth that is more than three standard deviations above the average for blacks.

\section{Conclusion}

The racial gap in homeownership remains one of the most enduring and pernicious features of racial stratification in the US, driving persistent racial disparities in the accumulation of wealth, the maintenance of residential stability, and a variety of ancillary social and economic outcomes. According to prevailing theoretical argument, understanding the factors that help to maintain this gap in homeownership requires attention to a wide range of factors, including racial differences in income, education, wealth, and the economic characteristics of extended networks, as well as financial exchanges within these networks. The research presented here offers a more comprehensive test of these dynamics than has been provided in past research. We use longitudinal data from the Panel Study of Income 
Dynamics to examine how access to financial resources in the extended family affects the levels of wealth among nonowners and how these resources subsequently affect the likelihood of transitioning into homeownership.

Several conclusions are worth highlighting here. First, our findings suggest that the economic conditions of the extended family have substantial effects on the accumulation of wealth among nonowners. Both the average level of wealth and the share of extended family member in poverty are associated with significantly higher levels of wealth among nonowners, and these effects emerge net of individual characteristics, including the education and income of the householder. Moreover, highlighting a second important conclusion, these effects of extended-family resources explain a substantial portion of the overall racial gap in wealth among nonowners. Thus, the significantly higher level of wealth among white nonowners versus black nonowners appears to be partly attributable to their access to extended-family networks with higher average levels of wealth and lower levels of poverty. However, even after holding constant the economic characteristics of households and their extended families, wealth levels of black nonowners are substantially lower than whites.

Third, we find that, even independent of education, income, and a wide range of other determinants of housing attainment, access to wealth in the extended family is an important factor in the transition to ownership. For both white and black nonowners, extended-family wealth significantly improves the chances of transitioning into ownership, and the higher level of wealth among white extended families plays an important role in the overall racial difference in the likelihood of becoming an owner. Further, and extending Heflin and Patillo's (2002) findings about the link between ownership and having poor siblings, our results indicate that the transition to ownership is significantly influenced by the extent of poverty in the extended family. However, we find significant effects of extended-family poverty only for black households, not whites. Certainly, black householders are linked to extended families with substantially higher levels of poverty, but the effects of these family resources on the transition to ownership are significantly more important for black than for white householders as well. Consistent with the weak version of the stratification perspective, this finding seems to indicate that, regardless of whether the extended family contains a high percentage of poor members, white householders are more likely to make the transition to ownership whereas for blacks the transition is much more contingent on the relationship to an extended family with a high level of income sufficiency (low poverty).

We view these findings as important indicators of persistent disparities in housing opportunities facing black and white householders as they seek to make the transition to ownership. By the nature of racial segregation and segmented housing markets, the search for housing for black families is often limited to action spaces with a paucity of owned units. The lower supply of owning opportunities in black neighborhoods may thus increase the financial demands placed on black homeseekers, helping to explain the greater importance of extended-family resources for blacks than for whites. While evidence of the contemporary redlining of black neighborhoods is weak (Munnell et al. 1996), other forms of discrimination in lending markets endure, including higher rejection rates and less favorable mortgage terms for blacks than whites (Munnell et al. 1996, Oliver and Shapiro 1997; Ross and Yinger 2002). Such restrictions may further limit the prospects of homeownership among all but those blacks from the wealthiest and less-needy families. In contrast, homeownership remains a viable option among those whites from extended families with a variety of economic conditions. In addition, despite federal efforts to target potential minority homeseekers (Schwartz 2006), governmental homeownership programs disproportionately aid previous owners and those in the middle to upper economic strata 
(Olsen 2007), possibly exacerbating the disparity in the likelihood of ownership between low- and high-status blacks observed in our study.

Yet despite the apparent importance of extended-family resources for black householders, a fourth finding of interest is that the effects of these extended-family resources on the likelihood of transitioning to ownership works partially through households' own wealth level, but not through the direct receipt or provision of help. While receiving financial help from outside the family in the years leading up to the observation period does influence the likelihood of making the ownership transition, it does so in a negative manner, drawing attention to the simple point that regardless of their own level of wealth, receiving financial assistance from others may reflect a level of financial dependence that undermines the ability to secure a mortgage or the willingness to take the financial risk of purchasing a home. Most importantly, however, controlling for the provision and receipt of financial transfers does not alter the effects of extended-family wealth, poverty, or the racial differences therein in any meaningful way.

Several possible dynamics might help to explain this weak mediating effect of economic help from others. First, it is possible that information on financial assistance received from others is simply unreliable if householders are loathe to admit the receipt of help. This might be especially true among those considering the transition to ownership given that lenders often frown on gifts from others as the source for down payments. However, assuming unreliable measurement would lead to the expectation of a null effect of help receipt on the transition to ownership, an expectation inconsistent with the significant effect observed in our results.

A second possibility is that our measures of help from others do not effectively capture some of the main types of financial assistance that might facilitate a transition to ownership. For example, parents and other family members with accessible resources might choose to absorb the costs of basic household expenses or make other direct purchases during a household's time of financial need. Such financial help is unlikely to show up in measures of direct financial transfers from outside the household but is still more likely to occur for those from wealthier extended families, and is likely to play an important role in the ability to transition from renting to owning a home. In a related way, renters from wealthier extended families may simply be more willing to take the financial risks associated with buying a home, knowing that extended-family resources may be available if the need arises. In contrast, those households associated with extended families with lower levels of wealth and higher levels of financial need will be unable to count on such a financial safety net (Conley 1999). Thus, the transition to ownership among those from higher-resource families is likely to be enhanced even in the absence of direct money transfers. Finally, those from more affluent upbringings may attach greater value to homeownership than those from more modest ones.

While future research should attempt to directly test these specific mechanisms, the research presented here indicates that financial characteristics - both wealth and poverty - in the extended family play an important role in both wealth accumulation prior to homeownership and the transition to homeownership. And given large racial differences in the average income and wealth of households making up family networks, these extended-family resources explain a considerable portion, but far from all, of the overall black-white difference in household wealth levels. Thus, considering these characteristics provides important insights to the processes through which large racial disparities in wealth are perpetuated from generation to generation. 


\section{Highlights}

1. We examine how extended-family resources shape the transition to homeownership.

2. Extended-family wealth and poverty contribute to racial inequalities in wealth.

3. Extended-family wealth positively affects the probability of becoming a homeowner.

4. The likelihood of ownership is negatively affected by family poverty among blacks.

5. With these controls, blacks remain less likely to become homeowners than whites.

\section{Acknowledgments}

We thank Editor Wright and two anonymous reviewers for their constructive feedback and useful suggestions, as well as Rachel Connelly, Marylee Taylor, and Lowell Taylor for comments on earlier versions of this paper.

\section{References}

Alba, Richard D.; Logan, John R. Assimilation and Stratification in the Homeownership Patterns of Racial and Ethnic Groups. International Migration Review. 1992; 26:1314-1341.

Barakakova, Irina; Bostic, Raphael; Calem, Paul S.; Wachter, Susan M. Does Credit Matter for Homeownership? Journal of Housing Economics. 2003; 12:318-336.

Berry, Brent. What Accounts for Race and Ethnic Differences in Parental Financial Transfer to Adult Children in the United States? Journal of Family Issues. 2006; 27:1583-1604.

Bobo, Lawrence; Zubrinsky, Camille L. Attitudes on Residential Integration: Perceived Status Differences, Mere In-Group Preference, or Racial Prejudice? Social Forces. 1996; 74:883-909.

Boehm, Thomas P. Income, Wealth Accumulation, and First-Time Homeownership: An Intertemporal Analysis. Journal of Housing Economics. 3:16-30.

Charles, Camille Zubrinsky. Neighborhood Racial-Composition Preferences: Evidence from a Multiethnic Metropolis. Social Problems. 2000; 47:379-407.

Charles, Camille Zubrinsky. Won't You Be My Neighbor? Race, Class, and Residence in Los Angeles. New York, NY: Russell Sage Foundation; 2006.

Charles, Kerwin Kofi; Hurst, Charles. The Transition to Home Ownership and the Black-White Wealth Gap. The Review of Economics and Statistics. 2002; 84:281-297.

Chiteji, Ngina; Hamilton, Darrick. Family Matters: Kin Networks and Asset Accumulation in. In: Sherraden, Michael, editor. Inclusion in the American Dream: Assets, Poverty, and Public Policy. Cambridge: Oxford University Press; 2005.

Collins, William J.; Margo, Robert A. Race and Homeownership: A Century-Long View. Explorations in Economic History. 2001; 38:68-92.

Conley, Dalton. Being Black, Living in the Red: Race, Wealth, and Social Policy in America. Berkeley: University of California Press; 1999.

Cox, Donald. Intergenerational Caregiving and Exchange: Economic and Evolutionary Approaches. In: Booth, Alan; Crouter, Ann C.; Bianchi, Suzanne M.; Seltzer, Judith A., editors. Intergenerational Caregiving. Washington D.C.: Urban Institute; 2008. p. 81-126.

Crowder, Kyle D. Racial Stratification in the Actuation of Mobility Expectations: Microlevel Impacts of Racially Restrictive Housing Markets. Social Forces. 2001; 79:1377-1396.

Crowder, Kyle; South, Scott; Chavez, Erick. Wealth, Race, and Inter-Neighborhood Migration. American Sociological Review. 2006; 71:72-94. 
Currarini, Sergio; Jackson, Matthew O.; Pin, Paolo. An Economic Model of Friendship: Homophily, Minorities, and Segregation. Econometrica. 2009; 77(4):1003-1045.

Di, Zhu Xiao; Liu, Xiaodong. The Importance of Wealth and Income in the Transition to Homeownership. Cityscape. 2007; 9:137-151.

Duncan, Greg J.; Hill, Daniel H. Assessing the Quality of Household Panel Data: The Case of the Panel Study of Income Dynamics. Journal of Business and Economic Statistics. 1989; 7:441-452.

Ellen, Ingrid Gould. Sharing America's Neighborhoods: The Prospects for Stable Integration. Cambridge: Harvard University Press; 2000.

Eriksen, Shelley; Gerstel, Naomi. A Labor of Love or Labor Itself: Care Work Among Adult Brothers and Sisters. Journal of Family Issues. 2002; 23:836-856.

Fischer, Mary. The Relative Importance of Income and Race in Determining Residential Outcomes in U.S. Urban Areas. Urban Affairs Review. 2003; 38:669-696.

Grieger, Lloyd D.; Danziger, Sheldon; Schoeni, Robert. Accurately Measuring the Trend in Poverty in the United States Using the Panel Study of Income Dynamics. Journal of Economic and Social Measurement. 2009; 34:105-117.

Heflin, Colleen M.; Pattillo, Mary. Poverty in the Family: Race, Siblings, and Socioeconomic Heterogeneity. Social Science Research. 2006; 35:804.

Heflin, Colleen M.; Pattillo, Mary. Kin Effects on Black-White Account and Home Ownership. Sociological Inquiry. 2002; 72:220-239.

Hill, Martha S. The Panel Study of Income Dynamics: A User's Guide. Newbury Park, CA: Sage; 1992.

Hochschild, Jennifer L. Facing up to the American Dream: Race, Class, and the Soul of the Nation. Princeton, NJ: Princeton University Press; 1995.

Iceland, John; Wilkes, Rima. Does Socioeconomic Status Matter? Race, Class, and Residence. Social Problems. 2006; 54:248-273.

Immergluck, Dan. Foreclose: High-Risk Lending, Deregulation, and the Undermining of America's Mortgage Market. Ithaca, NY: Cornell University Press; 2009.

Jayakody, Rukmalie. Race Differences in Intergenerational Financial Assistance: The Needs of Children and the Resources of Parents. Journal of Family Issues. 1998; 19:508-533.

Keister, Lisa A. Wealth in America: Trends in Wealth Inequality. New York: Cambridge University Press; 2000.

Krysan, Maria. Whites Who Say They'd Flee: Who Are They, and Why Would They Leave? Demography. 2002; 39:675-696. [PubMed: 12471849]

Krysan, Maria; Couper, Mick P.; Farley, Reynolds; Forman, Tyrone A. Does Race Matter in Neighborhood Preferences: Results from a Video Experiment. American Journal of Sociology. 2009; 115:527-559.

Krysan, Maria; Farley, Reynolds; Couper, Mick P. In the Eye of the Beholder: Racial Beliefs and Residential Segregation. Du Bois Review: Social Science Research on Race. 2008; 5:5-26.

Lee, Yean-Ju; Aytac, Isik A. Intergenerational Financial Support among Whites, African Americans, and Latinos. Journal of Marriage and the Family. 1998; 60:426-441.

Massey, Douglas; Denton, Nancy. American Apartheid. Cambridge: Harvard University Press; 1993.

Mayer, Christopher J.; Engelhardt, Gary V. Gifts, Down Payments, and Housing Affordability. Journal of Housing Research. 1996; 7:59-77.

McGarry, Kathleen; Schoeni, Robert F. Transfer Behavior in the Health and Retirement Study: Measurement and the Redistribution of Resources within the Family. Journal of Human Resources. 1995; 30:S184-S226.

McPherson, Miller; Smith-Lovin, Lynn; Cook, James M. Birds of a Feather: Homophily in Social Networks. Annual Review of Sociology. 2001; 27:415-444.

Menchik, Paul L.; Jianakopolos, Nancy Ammon. Black-White Wealth Inequality: Is Inheritance the Reason? Economic Inquiry. 1997; 35:428-442.

Morenoff, Jeffrey; Sampson, Robert; Raudenbush, Stephen. Neighborhood Inequality, Collective Efficacy, and the Spatial Dynamics of Homicide. Criminology. 2001; 39:517-560. 
Oliver, Melvin; Shapiro, Thomas. Black Wealth, White Wealth: A New Perspective on Racial Inequality. New York: Routledge; 1995.

Olsen, Edgar O. Opportunity and Ownership Project (Report No. 2). Washington, DC: Urban Institute; 2007. Promoting Homeownership among Low-Income Households.

Perin, Constance. Everything In Its Place: Social Order and Land Use in America. Princeton, NJ: Princeton University Press; 1977.

Raley, R Kelly. Black-White Differences in Kin Contact and Exchange Among Never Married Adults. Journal of Family Issues. 1995; 16:77-103.

Rohe, William M.; McCarthy, George; Van Zandt, Shannon. Working Paper 00-01. Washington, D.C.: Research Institute for Housing America; 2000. The Social Benefits and Costs of Homeownership: A Critical Assessment of the Research.

Rosenbaum, Emily. Racial/Ethnic Differences in Home Ownership and Housing Quality, 1991. Social Problems. 1996; 43:403-426.

Roschelle, Anne. No More Kin: Exploring Race, Class, and Gender in Family Networks. Thousand Oaks, CA: Sage; 1997.

Rohe, William M.; Watson, Harry L. Chasing the American Dream: New Perspectives on Affordable Homeownership. Ithaca, NY: Cornell University Press; 2007.

Ross, Stephen L.; Yinger, John. The Color of Credit: Mortgage Discrimination, Research Methodology, and Fair-Lending Enforcement. Cambridge, MA: MIT Press; 2002.

Rugh, Jacob S.; Massey, Douglas S. Racial Segregation and the American Foreclosure Crisis. American Sociological Review. 2010; 75:629-651.

Schwartz, Alex F. Housing Policy in the United States: An Introduction. New York: Routledge; 2006.

Shapiro, Thomas L. The Hidden Cost of Being African American. Oxford, UK: Oxford University Press; 2004.

Simmons, Patrick A. Fannie Mae Foundation Census Note 07. Fannie Mae Foundation; 2001. Changes in Minority Homeownership During the 1990s.

Solon, Gary. Intergenerational Income Mobility in the United States. American Economic Review. 1992; 82:393-408.

Squires, Gregory D.; Kim, Sunwoong. Does Anybody Who Works Here Look Like Me: Mortgage Lending, Race, and Lender Employment. Social Science Quarterly. 1995; 76:823-838.

Stack, Carol. All Our Kin: Strategies for Survival in a Black Community. New York: Harper \& Row; 1974.

StataCorp. Stata Multivariate Statistics Reference Manual, Release 11.0. College Station, TX: Stata Corporation; 2009.

Stuart, Guy. Discriminating Risk: The U.S. Mortgage Lending Industry in the Twentieth Century. Ithaca, NY: Cornell University Press; 2003.

Sudarska, Niara. The Strength of Our Mothers: African and African-American Women and Families: Essays and Speeches. Trenton, NJ: Africa World; 1996.

U.S. Census Bureau. Net Worth and Asset Ownership of Households: 2004. Washington: U.S. Census Bureau; 2010.

Wilson, William J. The Truly Disadvantaged: The Inner City, the Underclass, and Public Policy. Chicago, IL: University of Chicago; 1987.

Yinger, John. Closed Doors, Opportunities Lost: The Continuing Costs of Housing Discrimination. New York: Russell Sage; 1995. 


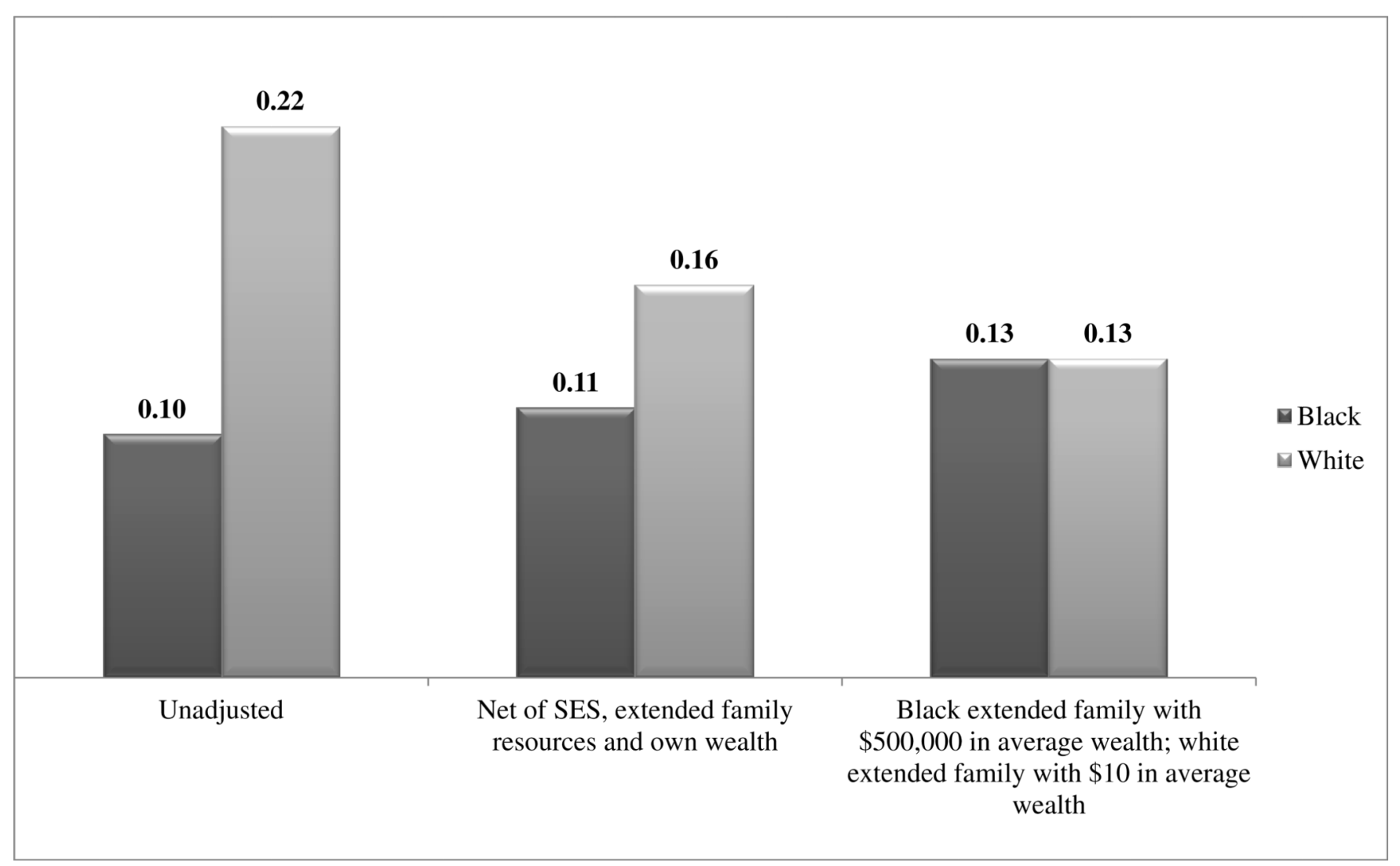

Figure 1. Predicted probabilities of transitioning from renting to owning between time $t$ and $t+1$, black and white non-owners

Note: Adjusted probabilities include all control variables, set at their grand means. 
Table 2

Regression coefficients predicting nonowners' logged household wealth

\begin{tabular}{|c|c|c|c|}
\hline & (1) & (2) & (3) \\
\hline \multirow[t]{2}{*}{ Black } & $-2.69^{* * *}$ & $-1.42^{* * *}$ & $-.87^{* * * *}$ \\
\hline & $(.10)$ & $(.09)$ & $(.09)$ \\
\hline \multirow[t]{2}{*}{ Extended-family wealth (logged) } & & & $.19^{* * * *}$ \\
\hline & & & $(.01)$ \\
\hline \multirow[t]{2}{*}{ Extended-family percent in poverty } & & & $-.01^{* * * *}$ \\
\hline & & & $(.00)$ \\
\hline \multirow[t]{2}{*}{ Age } & & $.02^{* * * *}$ & $.02^{* * * *}$ \\
\hline & & $(.00)$ & $(.00)$ \\
\hline \multirow[t]{2}{*}{ Female-headed household } & & $-.64^{* * *}$ & $-.59^{* * *}$ \\
\hline & & $(.09)$ & $(.09)$ \\
\hline \multirow[t]{2}{*}{ Educational attainment } & & $.10^{* * * *}$ & $.06^{* * * *}$ \\
\hline & & $(.02)$ & $(.02)$ \\
\hline \multirow[t]{2}{*}{ Taxable income (logged) } & & $1.68^{* * *}$ & $1.50^{* * *}$ \\
\hline & & $(.06)$ & (.06) \\
\hline \multirow[t]{2}{*}{ Year } & & $-.02 * *$ & $-.03^{* * * *}$ \\
\hline & & $(.01)$ & $(.01)$ \\
\hline \multirow[t]{2}{*}{ Constant } & $.23^{* * * *}$ & $28.97^{* * *}$ & $57.39^{* * *}$ \\
\hline & $(.07)$ & $(12.39)$ & (12.34) \\
\hline R-squared & .08 & .22 & .24 \\
\hline
\end{tabular}

Notes: $\mathrm{N}=35,776$ person periods ( $\mathrm{N}=8,127$ persons); Robust standard errors in parentheses;

p $<.05$;

*** $\mathrm{p}<.01$

**** $<.001$ 


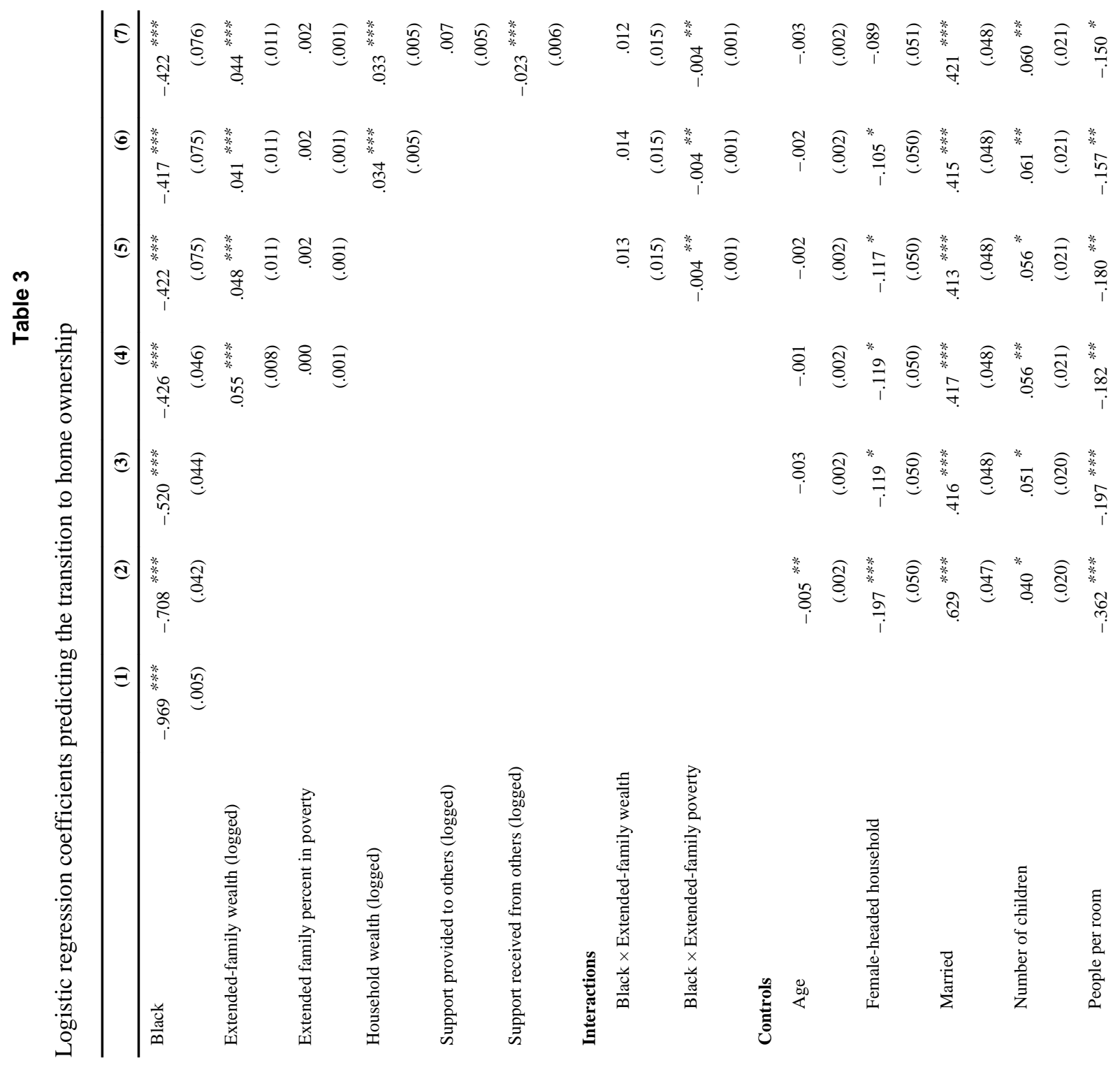




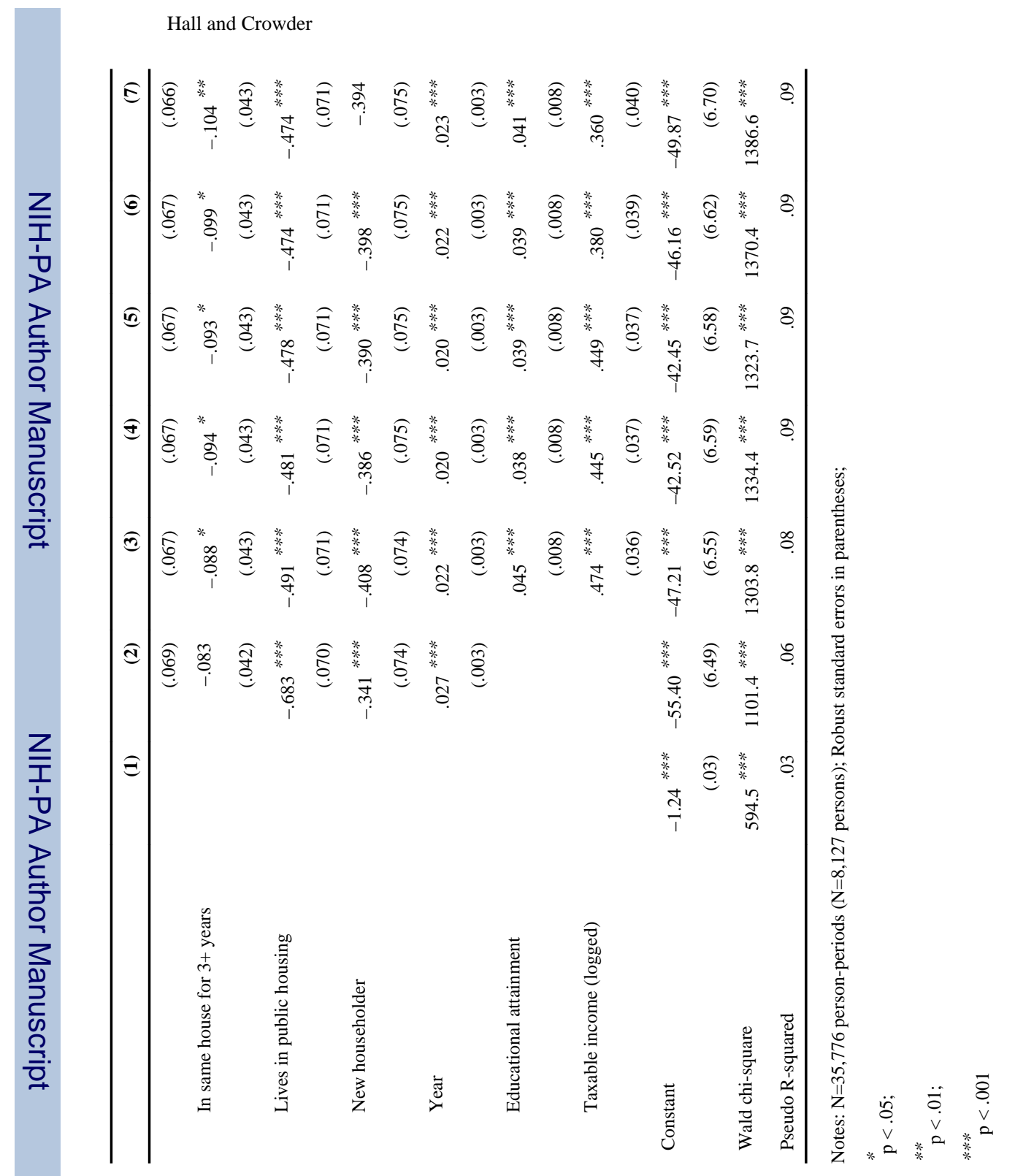

